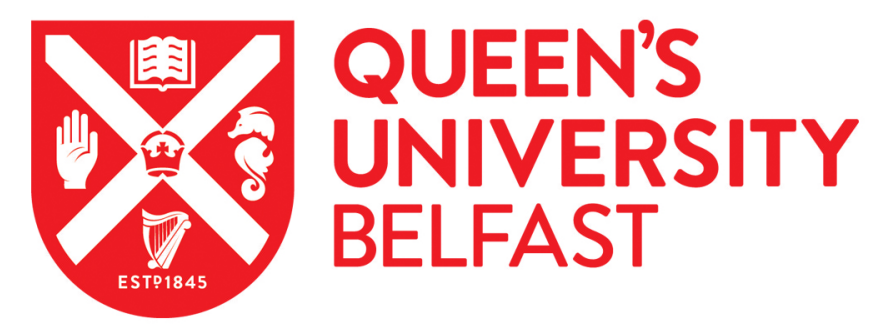

\title{
Behaviour of normally consolidated clay containing isolated solid inclusions
}

Sivakumar, V., Donohue, S., Rødvand, L., Nanda, S., \& Tripathy, S. (2018). Behaviour of normally consolidated clay containing isolated solid inclusions. Proceedings of the ICE - Geotechnical Engineering, 171(4), 345-356. https://doi.org/10.1680/jgeen.17.00131

Published in:

Proceedings of the ICE - Geotechnical Engineering

Document Version:

Peer reviewed version

Queen's University Belfast - Research Portal:

Link to publication record in Queen's University Belfast Research Portal

Publisher rights

( 2018 ICE Publishing. This work is made available online in accordance with the publisher's policies. Please refer to any applicable terms of use of the publisher.

\section{General rights}

Copyright for the publications made accessible via the Queen's University Belfast Research Portal is retained by the author(s) and / or other copyright owners and it is a condition of accessing these publications that users recognise and abide by the legal requirements associated with these rights.

Take down policy

The Research Portal is Queen's institutional repository that provides access to Queen's research output. Every effort has been made to ensure that content in the Research Portal does not infringe any person's rights, or applicable UK laws. If you discover content in the Research Portal that you believe breaches copyright or violates any law, please contact openaccess@qub.ac.uk. 


\title{
Behaviour of normally consolidated clay containing isolated solid inclusions
}

\author{
V. Sivakumar, S. Donohue L. Henderson, and N. Satyajeet
}

Queen's University Belfast

Submission to Geotechnical Engineering

Corresponding author:

V Sivakumar

School of Natural and Built Environment

Queen's University Belfast

BT7 1NN

v.sivakumar@qub.ac.uk 


\title{
Behaviour of normally consolidated clay containing isolated solid inclusions
}

\author{
V. Sivakumar, S. Donohue L. Henderson, and N. Satyajeet
}

\begin{abstract}
This paper examines the compression and strength characteristics of soils in relation to the presence of isolated solid inclusions such as colluvium and glacial till. Investigations were carried out on samples of kaolin with solid inclusions of angular crushed basalt and steel ball bearings (to represent rounded particles). It was observed that the presence of solid inclusions has a significant effect on the compression and strength characteristics of these composite soils and it is postulated that this behaviour is related to the formation of strong arches between the individual solid inclusions. This phenomenon was found to be subdued when the surface of the solid inclusion is smooth, suggesting that particle shape has also considerable influence on the mechanical behaviour of composite materials.
\end{abstract}

Key words: Clay, strength, compressibility 


\section{INTRODUCTION}

The engineering behaviour of natural soils is dependent on the constituent particles shape, size, arrangement, bonding and mineralogy as well as interactions at the particulate level (Olson and Mesri, 1970; Clemence and Finbarrm, 1981; Georgiannou et.al. 1991; Ruggeri, 2008; Clayton et.al. 2009; Clayton et.al. 2009; Goktepe and Sezer, 2010; Carrera et al. 2011; Ruggeri et.al. 2016). The level of participation in the transfer of inter-particle contact stresses by different particle types and sizes within the soil matrix dictates the stress-strain behaviour and the resistance it can offer under different loading conditions (Thevanayagam et.al. 2002; Cabalar and Hasan, 2013; Ruggeri et.al. 2016).

Although a significant portion of natural soils are poorly graded, consisting of particles of a range of different sizes ranging from clay $(\leq 0.002 \mathrm{~mm})$ to boulders $(>630 \mathrm{~mm})$, geotechnical practice broadly classifies soils as being either fine grained or coarse grained. Morainal deposits (e.g. tills), hillwash deposits (e.g. colluvium) and submarine mass flow deposits (e.g. diamictite) are just some examples of broadly graded composite (i.e. clay-gravel mix) materials. A number of researchers have investigated the influence of granular content on the engineering behaviour of composite soils (e.g. Holtz and Willard, 1956; Muir-Wood and Kumar, 2000; Vallejo and Mawby, 2000; Ni et.al. 2004; Jafari and Shafiee, 2004; Prakasha and Chandrasekaran, 2005; Long and Menkiti, 2007; Cabalar and Hasan, 2013; Ruggeri et.al. 2016). It is generally assumed that the overall behaviour of these soils is controlled by the predominant material, broadly described as "matrix dominated" where the granular inclusions are in suspension and "grain dominated" where the grains are physically in contact. The percentage of granular inclusions required for composite soil to behave like a grain dominated material is variable and depends on grading (Ruggeri et.al. 2016). One of the key aspects of the behaviour of composite soils is the interaction between the clay matrix and the solid inclusions, with respect to the volumetric responses and consequently the strength and deformation characteristics. Muir-Wood and 
Kumar, 2000 examined the impact of granular inclusions by varying the volumetric percentage of the two components (i.e. clay and sand). They suggested that externally measured volumetric responses were indicative of overall sample response, however "different things were happening in the filler material" (i.e. clay matrix). This was also suggested Jafari and Shafiee, 2004, who investigated this aspect through research on re-compacted kaolin-gravel mix. The purpose of this article is to investigate this aspect through a series of consolidated undrained compression tests on reconstituted composite materials with varying percentages of solid inclusions. The effect of grain shape is also investigated, through comparison of responses from kaolin samples included with either uniformly graded angular basalt or smooth stainless steel ball bearings.

\section{EXPERIMENTAL PROGRAMME}

In the investigations, the samples were formed from a slurry state containing solid inclusions of two different shapes. Two types of solid inclusion were investigated; (a) uniformly graded crushed angular basalt passing through a $3.1 \mathrm{~mm}$ sieve and retained on $2.3 \mathrm{~mm}$ sieve, and (b) 3 $\mathrm{mm}$ diameter smooth stainless steel balls. Since the specific gravities of the basalt and the kaolin are generally similar $\left(\mathrm{G}_{\mathrm{s}(\text { kaolin })}=2.65\right.$ and $\left.\mathrm{G}_{\mathrm{s}(\text { basalt })}=2.75\right)$, it was reasonable to assume that the percentages of solid inclusions, based on the dry masses of each component is the same as the volumetric percentages. The percentages of granular content, in the case of basalt, were: $0 \%, 20 \%, 40 \%$ and $60 \%$. The samples with and without solid inclusions were initially consolidated to various effective confining pressures ranging from $100 \mathrm{kPa}$ to $1300 \mathrm{kPa}$. When using ball bearings, the required mass of ball bearings was calculated by correcting for the density of ball bearings in relation to that of the basalt. For example, in the case of basalt, $400 \mathrm{~g}$ of kaolin dry powder was mixed with $100 \mathrm{~g}$ of basalt to represent $20 \%$ sold inclusions. As the density of the stainless steel $\left(7.60 \mathrm{~g} / \mathrm{cm}^{3}\right)$ was considerably higher than basalt $\left(2.75 \mathrm{~g} / \mathrm{cm}^{3}\right), 276 \mathrm{~g}$ of steel was added to the kaolin of the same mass so that, for a given volume of kaolin, the 
same percentage of basalt and steel inclusions were included in each sample. The kaolin slurry (without granular inclusion) was mixed at $1.5 \times$ LL (Liquid Limit $=70 \%$ ) and the required amount of solids was added to the slurry. The thoroughly mixed slurry was then consolidated onedimensionally to a vertical pressure of $200 \mathrm{kPa}$ in a sampling chamber of $50 \mathrm{~mm}$ internal diameter. The slurry was allowed to consolidate for two days, although the subsequent triaxial testing (discussed later) confirmed that a consolidation time of $12 \mathrm{hrs}$ was sufficient for complete dissipation of excess pore water pressure.

The sample was subsequently extruded and trimmed to a height of $100 \mathrm{~mm}$. Several trials were initially carried out (on both basalt and ball bearing at different percentage of inclusion) to optimise the sampling process. These trials indicated the volume of slurry required to make samples approximately $100 \mathrm{~mm}$ in height. The variation in the initial specific volume of the clay matrix (after one-dimensional compression) was approximately \pm 0.03 for a given percentage of granular inclusion. It was ensured that the pore water pressure parameter B was greater than 0.95 prior to consolidation and shearing. The samples were consolidated to various mean effective stresses under isotropic stress conditions $(100 \mathrm{kPa}, 200 \mathrm{kPa}, 400 \mathrm{kPa}, 800 \mathrm{kPa}$ and $1300 \mathrm{kPa}$ ) prior to undrained compression using the strain control method. There was a concern that the ball bearings could sink into the weak clay slurry under their own weight, however the strength of the slurry was sufficient enough to support them and prevented the ball bearings from accumulating at the base of the samples. This was confirmed by spreading ball bearings on the surface of slurry in a clear pot, covered with clingfilm and observing their position over three days.

\footnotetext{
A limited number of additional investigations were carried out on the composite materials. In these tests: (a) kaolin (prepared at 55\% water content) was mixed with $20 \%, 40 \%$ and $60 \%$ uniformly graded basalt inclusions and directly consolidated, in stages, in standard one- 
dimensional consolidation cells ( $70 \mathrm{~mm}$ diameter and $46 \mathrm{~mm}$ high) to $800 \mathrm{kPa}$, and (b) the kaolin slurry prepared at $1.5 \times \mathrm{LL}$ was mixed with approximately $40 \%$ inclusions and consolidated, in stages, in a Rowe cell (254 mm diameter and $300 \mathrm{~mm}$ high) to $800 \mathrm{kPa}$. In this investigation (i.e. (b), however, the granular inclusions are not basalt but hard form (BS3 type foam), broken into angular pieces having sizes between $28 \mathrm{~mm}$ and $50 \mathrm{~mm}$. The intention of this investigation was to directly assess the heterogeneous voids distributions in the composite material.

\section{RESULTS AND DISCUSSION}

\section{Compression}

The samples, prepared for the main investigations were progressively compressed under isotropic stress conditions (in a standard triaxial cell) from $100 \mathrm{kPa}$ to $1300 \mathrm{kPa}$ and the relevant observations are shown in Figure 1, where the mean effective pressure is presented. It is common practice to use the global void ratio as a tool to understand the pressure-void ratio relationships and the shear strength. However, this method may not be sufficient to fully explain the response of composite materials, as different behaviour may occur at a micro level (MuirWood and Kumar, 2000; Ni et.al. 2004, Thevanayagam et.al. 2002; Cabalar et.al, 2013; Ruggeri et.al. 2016 ). In this study, void ratio was calculated based on the volume of voids in the clay matrix (represented by $\mathrm{e}_{\mathrm{m}}$ ) and the solid volume of clay alone, assuming the water to be entirely contained within the clay matrix.

The pressure-void ratio $\left(\mathrm{e}_{\mathrm{m}}\right)$ relationship for samples with uniformly graded basalt inclusions was significantly affected by the presence of granular inclusions (Figure 1a). The clay sample with $60 \%$ inclusions subjected to approximately $1300 \mathrm{kPa}$, for example, achieved a similar matrix void ratio to the sample without inclusions, but subjected to $200 \mathrm{kPa}$ of mean effective stress. However, the slopes of the normal compression lines $(\lambda)$ remained reasonably similar with only 
a marginal increase when the granular content was increased to $60 \%$. The specific volume of the clay matrix, at this consolidation pressure $(1300 \mathrm{kPa})$ was about 2.26. However, the maximum void ratio of the basalt (under loose state at $100 \%$ ) was 1.20 , which confirms that the granular inclusions were not in contact. Thin sections of this material (after isotropic consolidation to $1300 \mathrm{kPa}$ ) have, however, shown some isolated contacts between the particles. The volumetric responses of the composite material containing steel ball bearings were distinctively different. The positions and the slopes of the normal compression lines were not significantly affected by the presence of up to $40 \%$ ball bearings (Figure 1b). A significant change in the position of the normal compression line was, however, observed with $60 \%$ inclusions.

There was a concern that the observed phenomena were only prevailing under isotropic loading and or that they occurred from the start of one-dimensional consolidation during the sampling process. In order to assess this, three one-dimensional consolidation tests were carried out on samples having $20 \%, 40 \%$ and $60 \%$ granular content. In these tests, samples were loaded from $50 \mathrm{kPa}$ to $800 \mathrm{kPa}$ in one-dimensional consolidation cells. The observed performances are shown in Figure 2 where the solid data points refer to the observations from one-dimensional consolidation tests and the open data points refer to the information presented in Figure 1. It should be noted that the data presented for the one-dimensional loading tests in Figure 2 are based on vertical stresses whereas the comparable data extracted from Figure 1 are based on isotropic stresses. The information gathered from the one-dimensional consolidation tests also intuitively confirms that the addition of granular inclusions leads to increased void ratio of the clay matrix when compared to clay without granular inclusions, at a given pressure. There appears to be some differences between the positions of the normal compression lines between the two different types of loading, however this can be attributed to the nature of the loadings i.e. isotropic in triaxial cell and anisotropic in one-dimensional consolidation cell. In addition, a 
small amount of side friction would be expected in the one-dimensional consolidation tests, between the sample and the rigid container. This effect is not taken into consideration in the present investigations. The following may explain the reasons for the observed volumetric responses of the composite material.

The clay matrix and the isolated granular inclusions are illustrated in Figure 3. In the absence of inclusions, the clay matrix does not experience significant shear strain under isotropic stress conditions, assuming that the clay matrix possesses isotropic stiffness properties. Although isotropic stress conditions are maintained on the boundary of the samples, the presence of angular inclusions creates an intense shear zone in the clay surrounding the inclusion due to the variation in stiffness between the individual materials and the mobility of the granular inclusions. Since the clay matrix is normally consolidated, the clay surrounding the solid inclusions undergoes strain hardening, resulting in a reduction in void ratio. If the inclusions are close enough, this hardening process forms strong bridges between the inclusions (Figure 3b). This phenomenon was also postulated by Jafari and Shafiee 2004, however in their studies the samples were compacted prior to further investigations. The formation of bridges is also affected by concentration of stresses in the clay between the solid inclusions. The development of such bridging is progressive with increasing consolidation pressure. As this arching/bridging mechanism develops, the clay matrix enclosed by the solid inclusions does not experience the full extent of the externally applied pressure and it becomes consolidated under a lower pressure. The void ratio of the material in this region could therefore be significantly higher than in the bridge.

Direct evidence of heterogeneous pore void distribution was obtained by measuring the distribution of void ratio in the sample. Due to difficulty in assessing the water content distribution in $50 \mathrm{~mm}$ diameter samples with basalt inclusions of smaller particles, two separate 
tests were carried out in a Rowe Cell (253mm diameter). The samples without and with granular inclusions ( $40 \%$ foam by volume of solids) were consolidated to $800 \mathrm{kPa}$ of vertical stress and the pressure-volume relationships for these two tests are illustrated in Figure 2. It is again remarkable that the position of the NCL for the sample included with $40 \%$ form falls above the NCL for $0 \%$ granular inclusions. The position of this line is close to the normal compression lines obtained on isotropically or one-dimensionally compressed samples having $40 \%$ granular inclusions. At the end of the tests, both samples (with and without granular inclusions) were extruded from the Rowe Cell and cut by band-saw at mid height to assess the void ratio distributions. The relevant observations are shown in Figure 4. Figure 4a illustrates the location of the granular inclusions (hard foam) within the clay matrix following the test (since the foam and kaolin were similar in colour it was difficult to distinguish the two components on the actual digital image). Figure $4 \mathrm{~b}$ shows the distributions of void ratio at various locations. Once again the observations have confirmed a strong heterogeneous void distribution in the sample with granular inclusions which was postulated by Muir-wood and Kumar, 2000 and Jafari and Shafiee, 2004.

In order to further confirm the above observations, several SEM images were acquired (5000x magnification) on the sample having $60 \%$ basalt inclusions, isotropically consolidated in the triaxial cell to $1300 \mathrm{kPa}$ (Figure 5). As shown, the packing of clay particles was tight and close together at location 2 (i.e. between the granular inclusions), whereas at locations 1 and 3 (i.e. away from the inclusions), the clay particles were relatively loose, supporting our hypothesis. However the authors agree the evidence shown is qualitative and quantification of varying pore size distribution would require further investigation in the form of 3D SEM images. In addition, discrete element modelling (DEM) could numerically validate the hypothesis presented above.

\section{Stress-strain behaviour}


The presence of granular inclusions generates heterogeneous pore void distributions and therefore the meaning of "undrained compression" is questionable as there can be redistribution of pore water in the voids, even though the overall volume of the sample is maintained constant. This can make the stress-strain behavior complex, and identifying the critical state can be difficult. Muir-Wood and Kumar, 2000 carried out an extensive investigation on kaolin-sand mix at various proportions and the samples were sheared under drained and undrained conditions. They used the maximum $\mathrm{q} / \mathrm{p}^{\prime}$ ratio as an indication of critical state, although there was no evidence presented in the article to confirm if an actual critical state was obtained. Carrera et.al. 2011 carried out an extensive investigation on Stava tailing in which the samples were reconstituted with different percentage of sand and fine particles in order to examine the liquefaction potential of composite material. These authors again used the maximum $q / p^{\prime}$ ratio as an indication of critical state. In a recent study, Ruggeri et.al. 2016 carried out a large number of tests on composite materials prepared at different percentages of granular inclusion and used the same technique to identify the critical state. In this study it was therefore assumed that the critical state was reached at maximum stress ratio $\left(\sigma_{1}^{\prime} / \sigma_{3}^{\prime}\right)$, which also corresponds to maximum $\mathrm{q} / \mathrm{p}^{\prime}$.

Figure $6(a, b, c)$ illustrates the stress-strain behaviour of clay containing various percentages of uniformly graded basalt, subjected to $1300 \mathrm{kPa}$ of initial consolidation pressure. The strain is based on the axial displacement in relation to original height of the sample. The behaviour observed in the test without inclusions is typical of normally consolidated clay, with the sample reaching critical state at about $14 \%$ axial strain. However, the behaviour changed as the percentage of granular content was increased. The samples without inclusions failed in shear plane (physically observed and indicated on Figure 6a) and the deviator stress gradually approached the residual state. The sample with $20 \%$ granular content also failed on shear 
Thin sections obtained on samples with $60 \%$ inclusions (isotropically compressed to $1300 \mathrm{kPa}$ ), demonstrated that the inclusions were generally isolated with only marginal interactions. It is therefore likely that inter-particle friction does not significantly contribute to the overall strength. The sample with $60 \%$ granular content consolidated to $1300 \mathrm{kPa}$ reached a maximum deviator stress of $620 \mathrm{kPa}$, which is only $40 \mathrm{kPa}$ less than the sample without inclusions (Figure $6 \mathrm{a}$ ). In the samples with $20 \%$ and $40 \%$ inclusions, the peak stresses were $590 \mathrm{kPa}$ and $550 \mathrm{kPa}$ respectively. There are two aspects that require further explanation: (a) overall the peak deviator stresses of the samples containing granular inclusions are high if it is assumed that the strength is only provided by the clay matrix and (b), if the poorly compressed clay were to be responsible for reduced strength, then the peak stress of the sample with $60 \%$ inclusions should be lower than that of the samples containing fewer inclusions. The arching effect, discussed above, could have contributed to the high strength observed in samples with inclusions. It is possible that continued shearing of the samples beyond their peak strengths destroyed these arches and exposed the enclosed clay to the externally applied pressures. If this were to be the case, the pore water pressure should continue to increase as shearing progressed, which was actually observed in the samples with inclusions (Figure 6b). The relatively high deviator stress measured in the sample with $60 \%$ granular content can be explained by isolated shearing between the aggregates. Figure $6 \mathrm{c}$ shows the stress ratio $\left(\sigma_{1}^{\prime} / \sigma_{3}^{\prime}\right)$ during the shearing process at initial consolidation pressure of $1300 \mathrm{kPa}$. 
Figure $6 \mathrm{~d}$ shows the stress paths for $20 \mathrm{CIU}$ tests carried out on samples with and without inclusions. In samples with granular contents of $20 \%$ and $40 \%$, the peak state (assumed to be critical state, based on maximum stress ratio and indicated by open circular data points for $60 \%$ granular inclusion) correlates reasonably well with the critical state line, identified from tests without inclusions, indicating that shearing was taking place in the clay. However, in the case of $60 \%$ gravel, the critical state line lies above the critical state line identified from $0,20 \%$ and $40 \%$ granular inclusion, implying the possibility of isolated shearing between inclusions. In the case of $0 \%$ granular inclusion, the slope of the post-peak stress path (i.e. approaching the residual state) is approximately 3. Similar observations have been reported by Georgiannou and Hight, 1994. However, as the percentage of granular inclusions increases, the slope of the stress path reduces, for example the post-peak stress path of the composite material with $20 \%$ granular content is approximately 2.9 and that for $40 \%$ and $60 \%$ granular contents are 2.05 and 1.85 respectively. These observations also agree with Carrera et.al. 2011. The reduction in the postpeak slope is largely attributed to continued development of pore water pressure as the shearing progressed through post peak state.

Figure 7 shows the void ratio $\left(e_{m}\right)$ plotted against the mean effective stress at critical state. For clarity, the data are presented in two separate figures: Figure 7a shows the NCL and CSL for $0 \%$ and $40 \%$ granular inclusions and Figure $7 \mathrm{~b}$ shows the same for $20 \%$ and $60 \%$ granular inclusion. It is remarkable that the NCL are parallel to CSL at all percentage content of granular inclusions and that, in general, the spacing between them remained unchanged. Muir-Wood and Kumar, 2000, presented data obtained on composite material subjected to fully drained shearing. In their studies the volumetric strains were generally unaffected by the percentage of granular inclusions. Although they did not present the NCL and CSL directly, their data also implies that the NCL may be parallel to the CSL at a given percentage of granular inclusions. Ruggeri et.al. 2016 presented $\mathrm{e}_{\mathrm{m}}$ (referred to as specific volume, $\mathrm{v}_{\mathrm{c}}$ ) for various combinations of 
fine-granular mix. Since all their tests were carried out at $400 \mathrm{kPa}$ of consolidation pressure, it was not possible to locate the NCL or CSL for a given granular inclusions. However, it is clear that the $e_{m}$ at critical state increases with the size of the granular inclusions, which agrees favourably with the observations presented here.

Unlike the tests with basalt inclusions, the peak deviator stresses of samples with $20 \%, 40 \%$ and $60 \%$ ball bearings are similar (Figure 8 ). This agrees with the earlier observations where the presence of up to $40 \%$ ball bearings did not have any significant influence on the position of the normal compression lines. The pore water pressure responses are generally similar among tests containing 0,20 and $40 \%$ inclusions (contrast to the observations made in basalt inclusion, Figure $6 \mathrm{~b}$ ) and significantly different at $60 \%$ ball bearings, (Figure 8 ). Unlike the test on $60 \%$ basalt (Figure 6a), the effect of localised shearing was substantially reduced on tests with the equivalent ball bearing content. Samples with $20 \%$ and $40 \%$ ball bearings failed in shear as the samples continued to deform, whereas the sample with $60 \%$ ball bearings continued to bulge. As discussed in the case of granular inclusion, the slope of the post peak stress path is 3 for $0 \%$ granular inclusions and remained approximately same for $20 \%$ and $40 \%$ ball bearing content. This slope reduced to 2.0 as the percentage of ball bearing increased to $60 \%$.

Figure 9 shows the variation of the effective angle of internal friction at the critical state (based on the maximum stress ratio), $\phi_{\mathrm{cv}}^{\prime}$. The $\phi_{\mathrm{cv}}^{\prime}$ for kaolin is approximately $21^{\circ}$. The inclusion of $20 \%$ and $40 \%$ basalt marginally reduced $\phi_{c v}^{\prime}$ by $0.7^{\circ}$, however, at $60 \%$ inclusions $\phi_{c v}^{\prime}$ increased by $2.3^{\circ}$. The inclusion of $20 \%$ ball bearings in place of basalt reduced the $\phi_{\mathrm{cv}}^{\prime}$ by $3.2^{\circ}$ (to $18^{\circ}$ ), however, further increases in the inclusion content increased $\phi_{\mathrm{cv}}^{\prime}$ to $19.9^{\circ}$ at a ball bearing content of $60 \%$. Ruggeri et.al. 2016 reported a progressive increase in angle of internal friction as the granular content was reduced from $100 \%$ to $0 \%$. However, only a small increase of $\phi_{\mathrm{cv}}^{\prime}$ 
was observed up to about $30 \%$ granular inclusions. The present investigation confirms this observation as $\phi_{c v}^{\prime}$ generally remains constant up to about $40 \%$ granular content. The increase in friction angle at $60 \%$ granular content can be attributed to isolated granular contacts (also observed in thin section). The frictional resistance between basalt and kaolin can be taken as the minimum friction angle of the two individual components of the composite material. In the present investigation it is kaolin which controls the minimum friction angle. However, when the ball beings were included as solid inclusion, the interface friction angle between ball bearings and surrounding clay is much lower than the $\phi_{\mathrm{cv}}^{\prime}$ of kaolin. This may explain why the friction angle initially dropped as the percentage of ball bearing was increased.

\section{CONCLUSIONS}

Investigations were carried out on samples of kaolin with granular inclusions of crushed angular basalt and smooth ball bearings to examine their effect on the compression and strength characteristics of clays. Isotropic compression and onedimensional consolidation tests revealed that granular inclusions have an influence on the pressure-void ratio characteristics of the clay matrix. It is thought that the zone surrounding the solid inclusions experiences intense shear deformation, leading to the formation of arches between inclusions. As this arching/bridging mechanism develops, the clay matrix enclosed by the solid inclusions does not experience the full extent of the externally applied pressure and it becomes under-consolidated and consequently heterogeneous void distribution in the clay matrix which was independently validated using SEM and water void ratio measurements. This phenomenon was found to be subdued when the surface of the granular inclusion was smooth, which suggests that particle shape has a considerable influence on the volumetric behaviour of composite materials. 
Increasing the granular content resulted in an increase in peak strength during shear loading on samples with basalt inclusions. This observation could also have been a product of the bridging mechanism between granular inclusions. Continued shearing of samples leads to destruction of these bridges, possibly exposing the enclosed clay to the externally applied pressures. This has resulted in continued build-up of pore water pressure even though the samples appeared to have reached critical state. In kaolin -basalt mix, there appears to be no significant change in friction angle until the granular content was up to $60 \%$. Particle shape was also found to have a considerable influence on the behaviour of the samples during shearing. The critical state friction angle reduced noticeably when the ball bearing contents were increased up to $40 \%$.

\section{ACKNOWLEDGEMENT}

The authors also wish to thank P J Carey Ltd, UK and V. Nathan, V.J Tech Ltd UK, for continuing their support for the geotechnical engineering research at Queens' University Belfast.

\section{REFERENCES}

Cabala,A.F. and Hasan, R.A., 2013. Compressional behaviour of various size/shape sand-clay mixtures with different pore fluids, Engineering Geology, Vol. 164, pp 36-49

Carrera, A., Coop, M., and Lancellotta.R. 2011. Influence of grading on the mechanical behaviour of Stava tailings Géotechnique 61, No. 11, 935-946.

Clayton, C.R.I, Abbireddy,C.O.R and Schiebel, R., 2009. A method of estimating the form of coarse particulates, Geotechnique, Vol 6, pp 496-501

Clemence and Finbarr(1981), Journal of the Geotechnical Engineering Div., ASCE, Vol. 107, GT3, pp. 305-317.

Goktepe, A.B. and Sezer, A., 2010. Effect of particle shape on density and permeability of sand. Geotechnical Engineering, Vol. 163, pp 207-320. 
Georgiannou, V.N., Hight, D.W and Burland, J.B. (1991). Behaviour of clayey sands under cyclic triaxial loading. Geotechnique, 41 (3). Pp 383-393.

Holtz,W.G., and Willard,M. (1956). Triaxial shear characteristics of clayey gravel soils. Journal of Geotechnical Engineering, ASCE, 82, pp 143-149

Jafari.M.K. and Shafiee.A. (2004). Mechanical behaviour of compacted composite clays. Canadain Geotechnical Journal. Vol. 41, pp 1152-1167.

Long, M. and Menkiti, C.O. (2007) Geotechnical properties of Dublin Boulder Clay. Géotechnique, Vol. 57, No. 7, 595-611.

Mesri,G. and Olson, R.E., 1970. Mechanism controlling the permeability of clays. Clays and clay minerals, Pergamon press, Vol. 19, pp 151-158

Muir-Wood, D., and Kumar, G.V., 2000. Experimental observations of behaviour of heterogeneous soil. Mechanics of frictional materails, Vol. 5, pp 373-398

Ni, Q., Tan, T. S., Dasari, G. R. \& Hight, D. W. (2004). Contribution of fines to the compressive strength of mixed soils Géotechnique 54, No. 9, 561-569.

Prakasha, K. S. \& Chandrasekaran, V. S. (2005). Behavior of marine sand-clay mixtures under static and cyclic triaxial shear. J. Geotech and Geoenvironmental Eng. ASCE 131, No. 2, $131-122$.

Ruggeri, P. , 2008. Comportamento meccanico di un terrenocomplesso a granulometria eterogenea. PhD thesis, Università Politecnica delleMarche, Ancona, Italy (in Italian).

Ruggeri,P., Segato, D. Fruzzetti, V.M.E., and Scarpelli, G., 2016. Evaluating the shear strength of a natural heterogeneous soil using reconstituted mixes. Geotechnique, Vol. 66 pp $941-946$

Soroush, A. \& Jigheh, H.S. 2009. Pre- and post-cyclic behavior of mixed clayey soils. Canadian Geotechnical Journal 46, 115-128. 
Thevanayagam, S., Shenthan, T., Mohan, S. \& Liang, J. (2002). Undrained fragility of clean sands, silty sands and sandy silts. J. Geotech and Geoenvironmental Eng. ASCE 128, No. $10,849-859$.

Vallejo, L.E. \& Mawby, R. 2000. Porosity influence on the shear strength of granular materialclay mixtures. Engineering Geology 58, 125-136. 
(a) Unformly graded
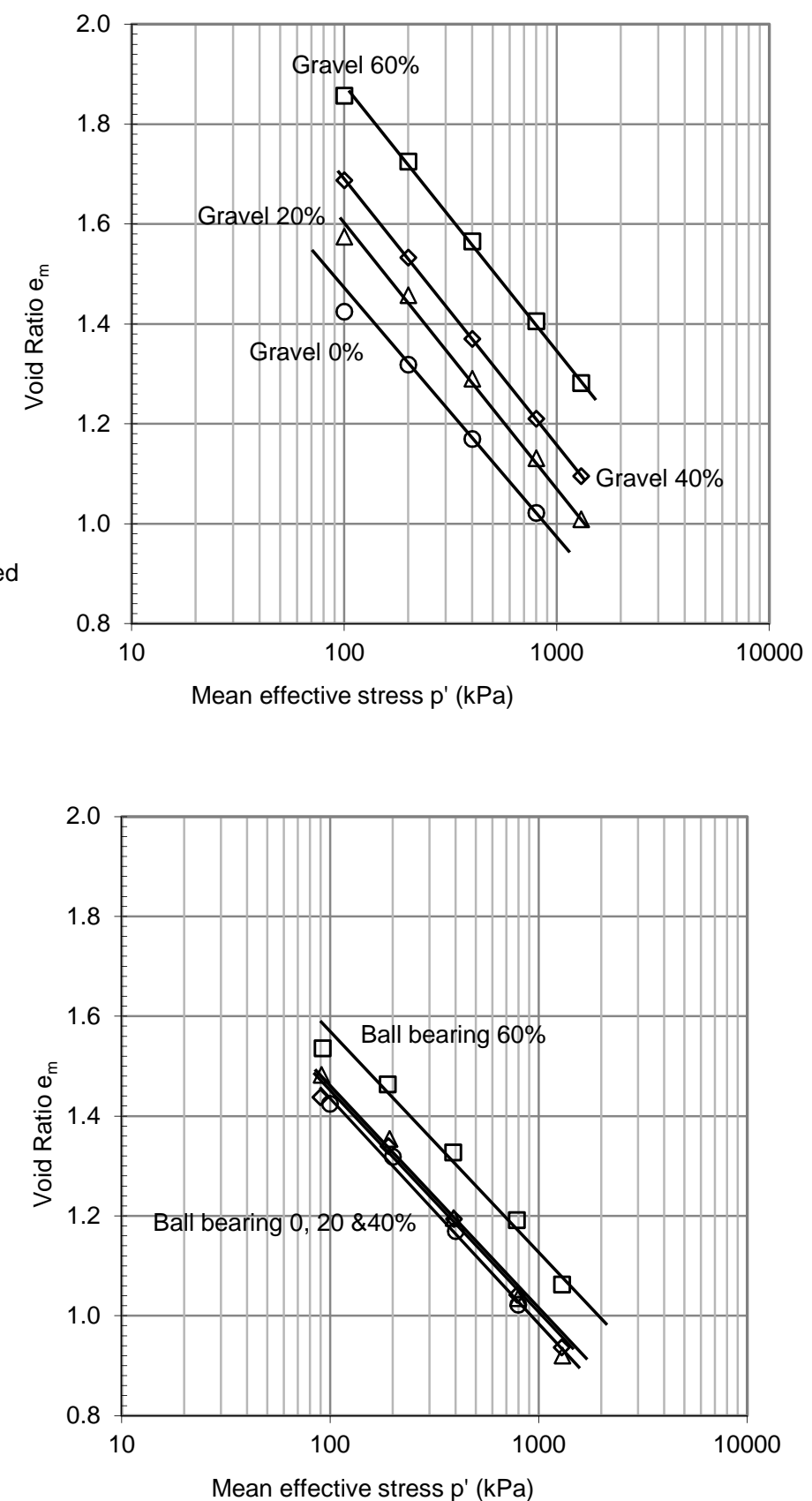

(b) Ball bearings

Mean effective stress $\mathrm{p}^{\prime}(\mathrm{kPa})$

Figure 1 Pressure-matrix void ratio relationships under isotropic stress conditions 


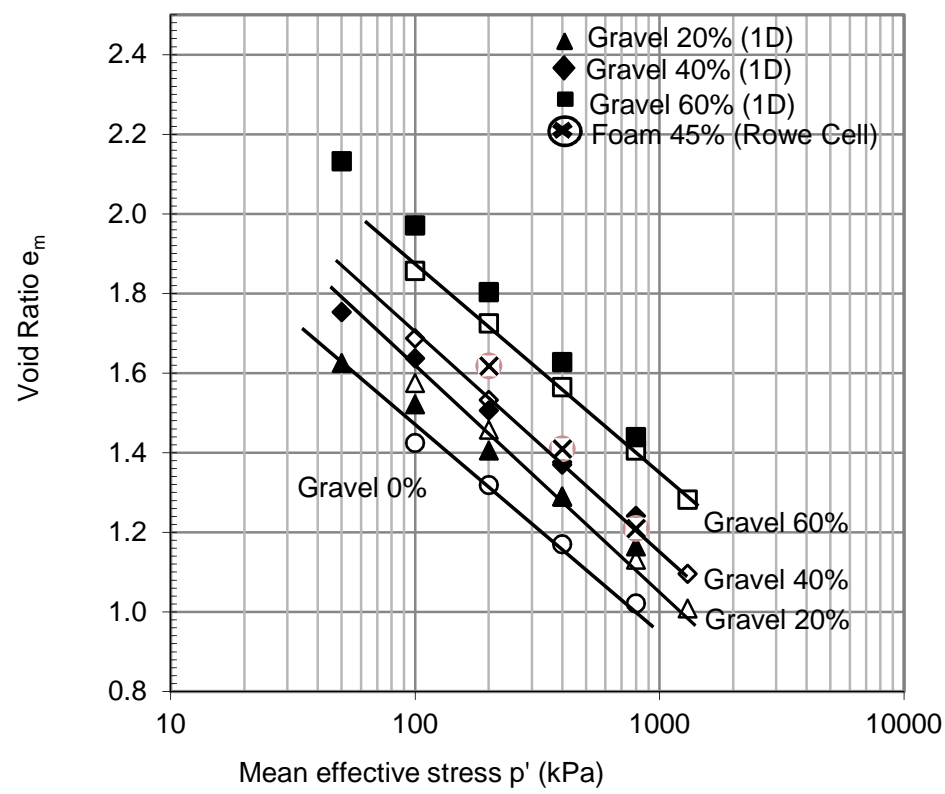

Figure 2 Pressure-matrix void ratio relationships under isotropic and onedimensional loading conditions 


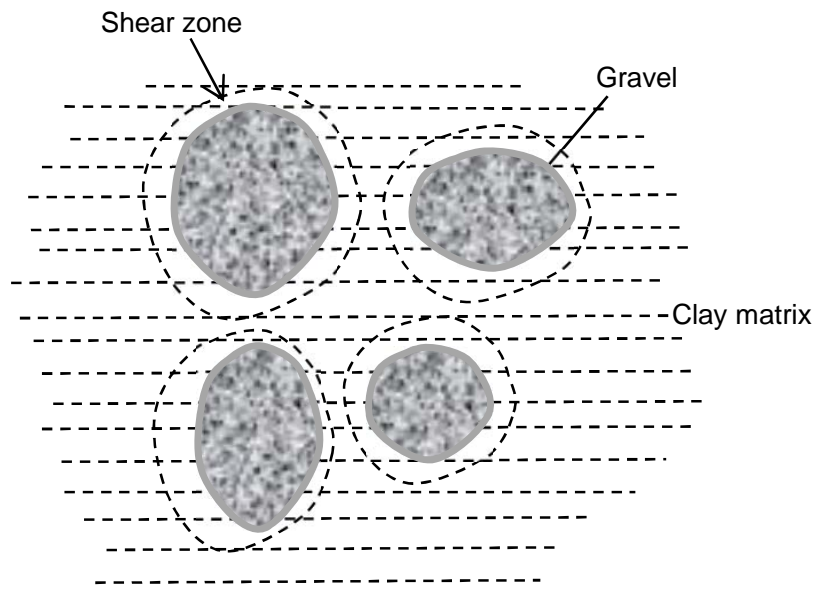

(a) Shear zone

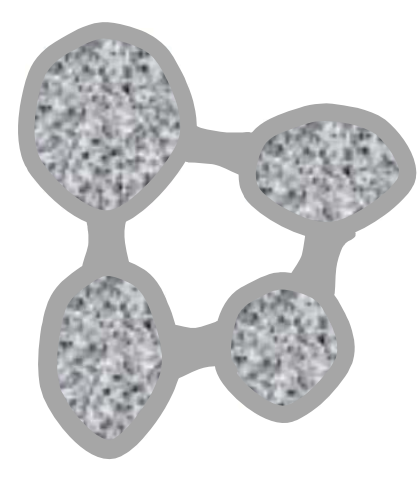

(b) Bridging between solid inclusions

Figure 3 Shear zone around the particles 


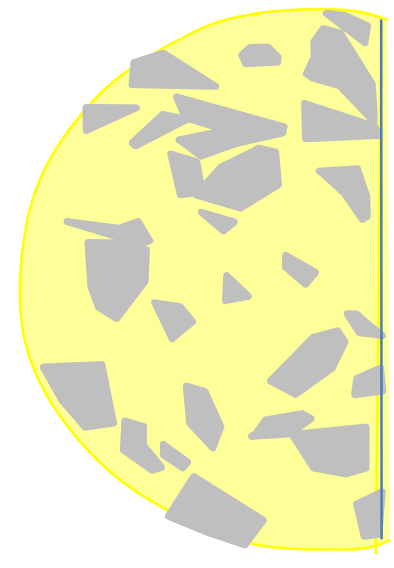

(a)Illustration of the section

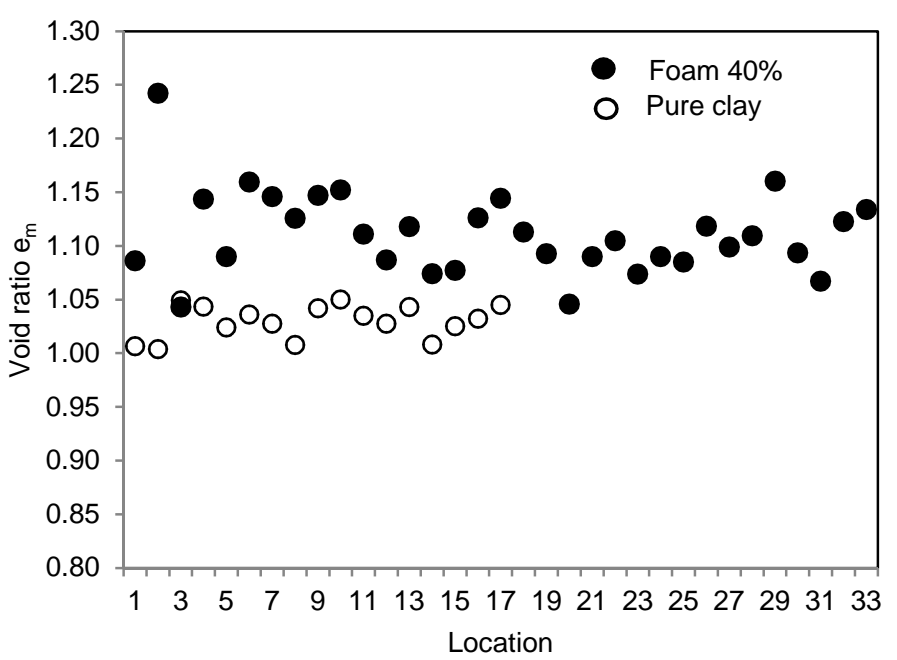

(b) Void ratio distribution

Figure 4 Void ratio distributions (Rowe cell consolidation with foam $0 \%$ and $40 \%$ ) 


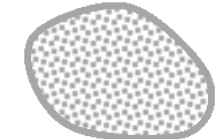

1

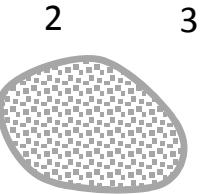

(a) Location 1 (away from the gravel)

(b) Location 2 (between the gravel)

(c) Location 3 (away from the gravel)
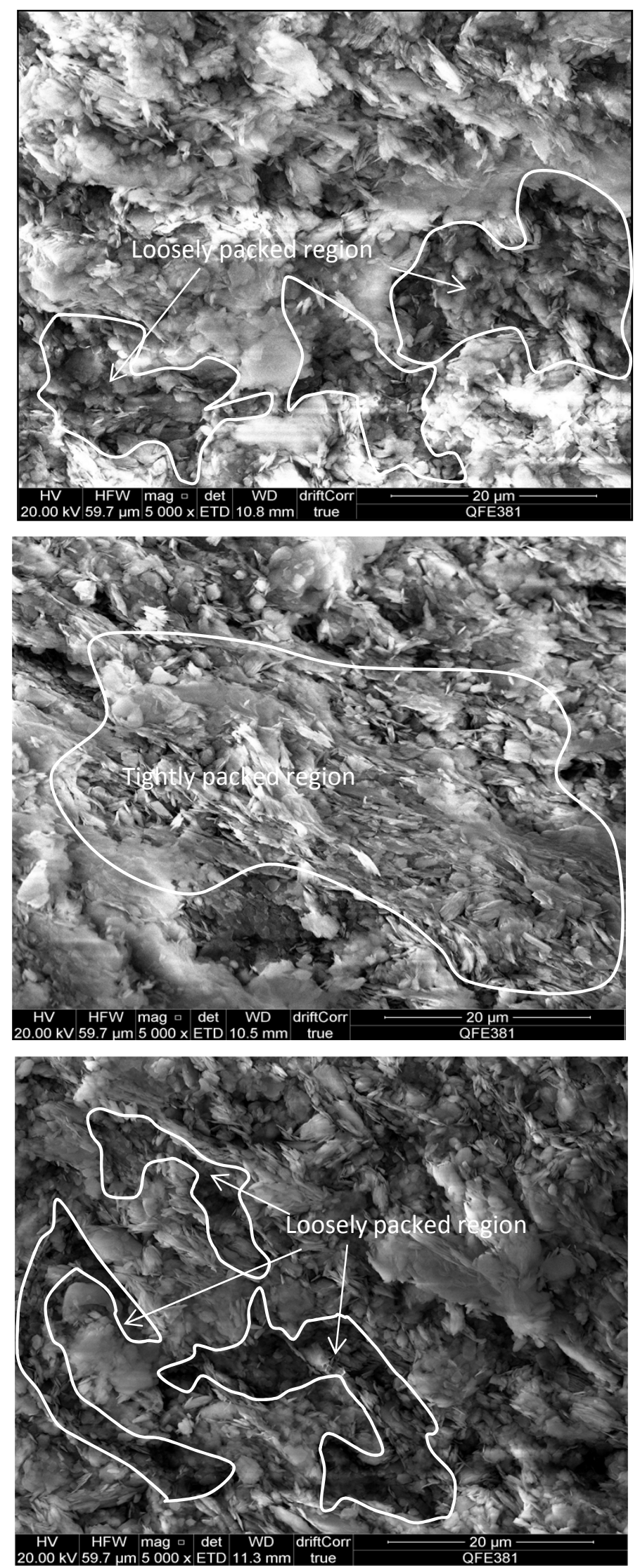

Figure 5 SEM images of clay matrix 

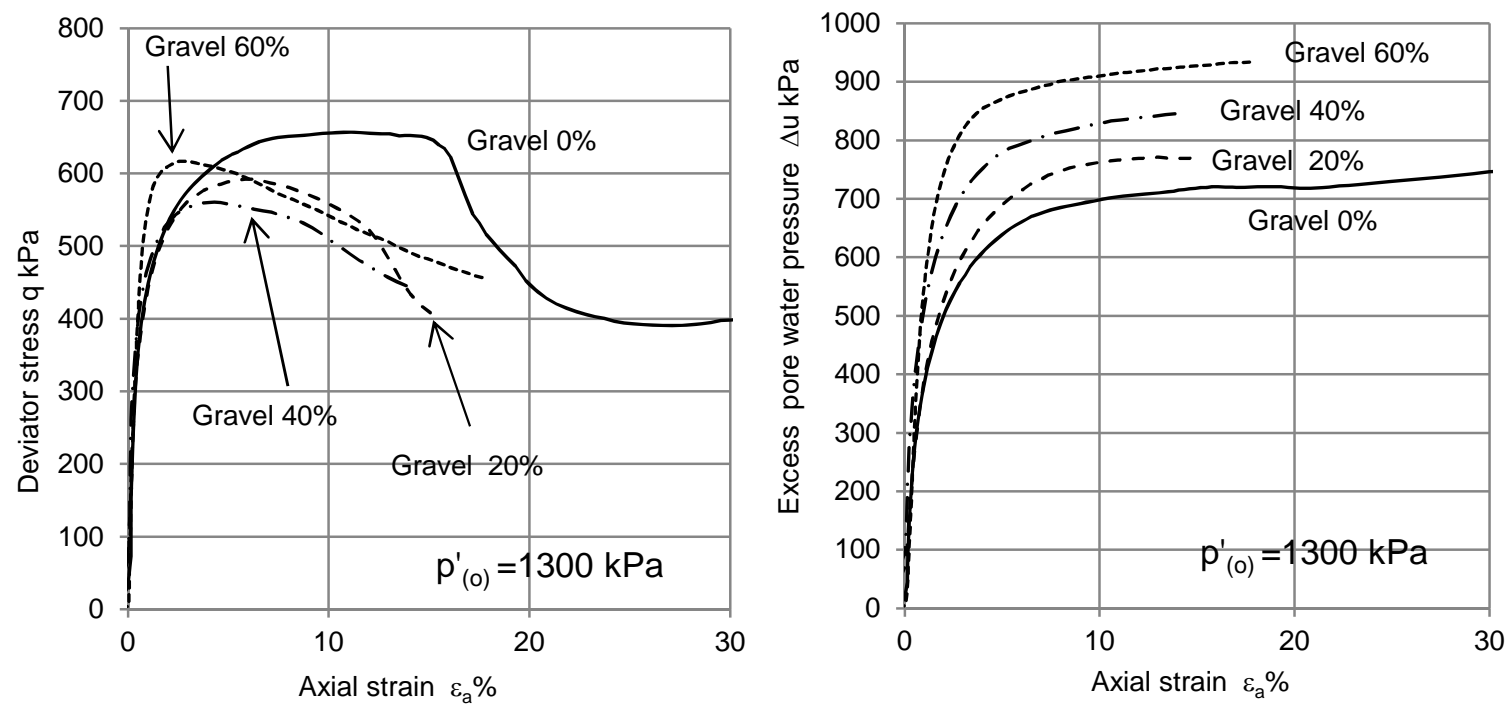

(a) Deviator stress vs axial strain

(b) Excess pore water pressure vs axial strain

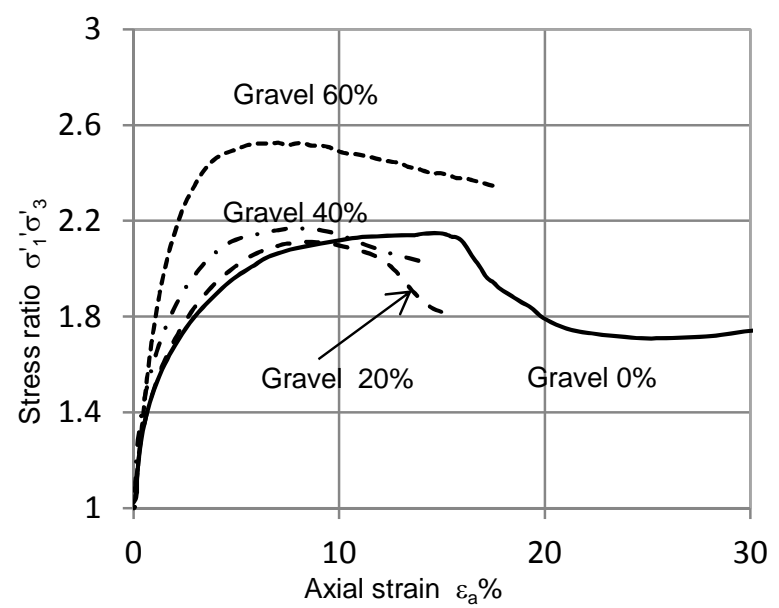

(c) Stress ratio vs axial strain

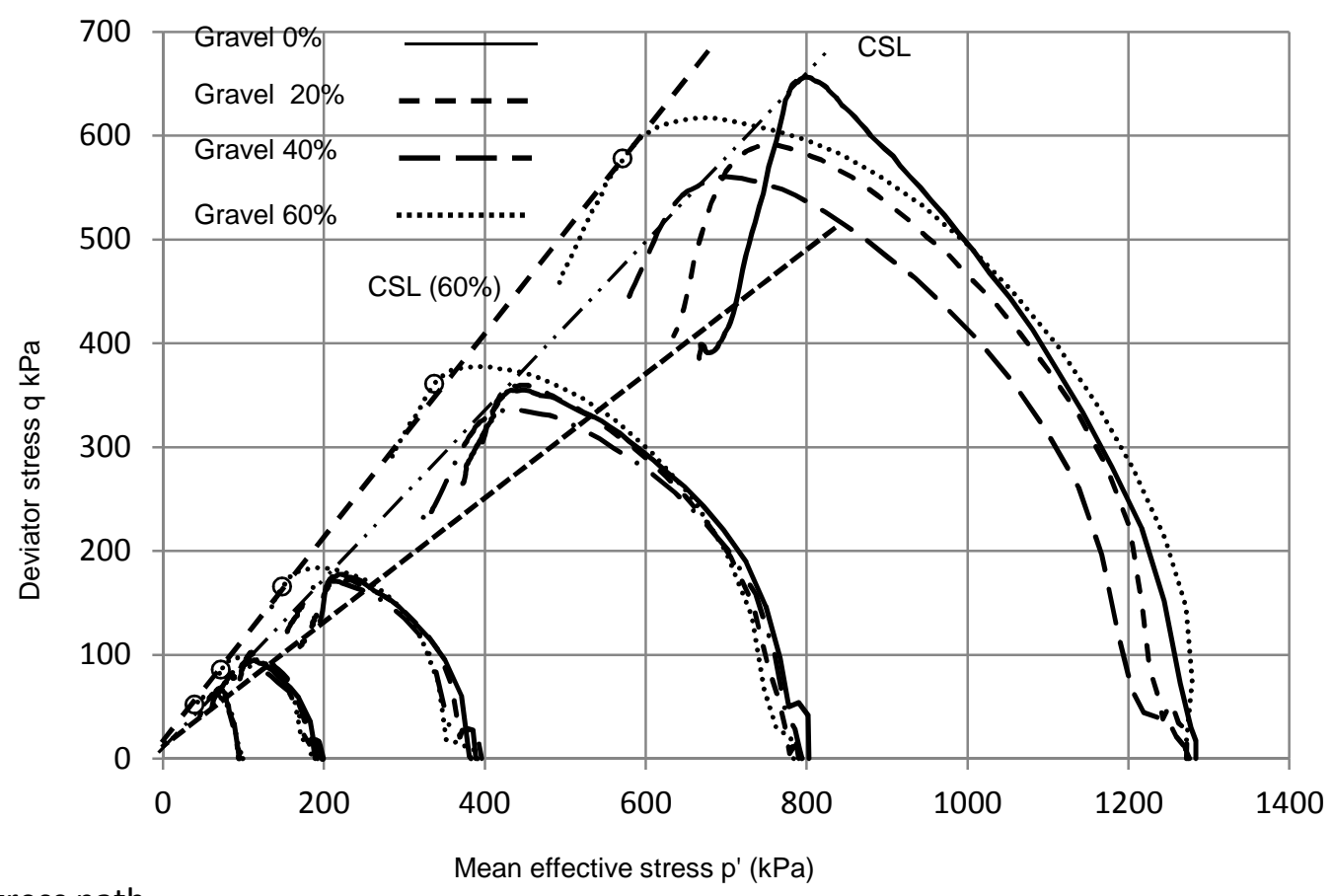

(d) Stress path

Figure 6 Stress-strain behaviour and stress paths: Uniformly graded basalt 

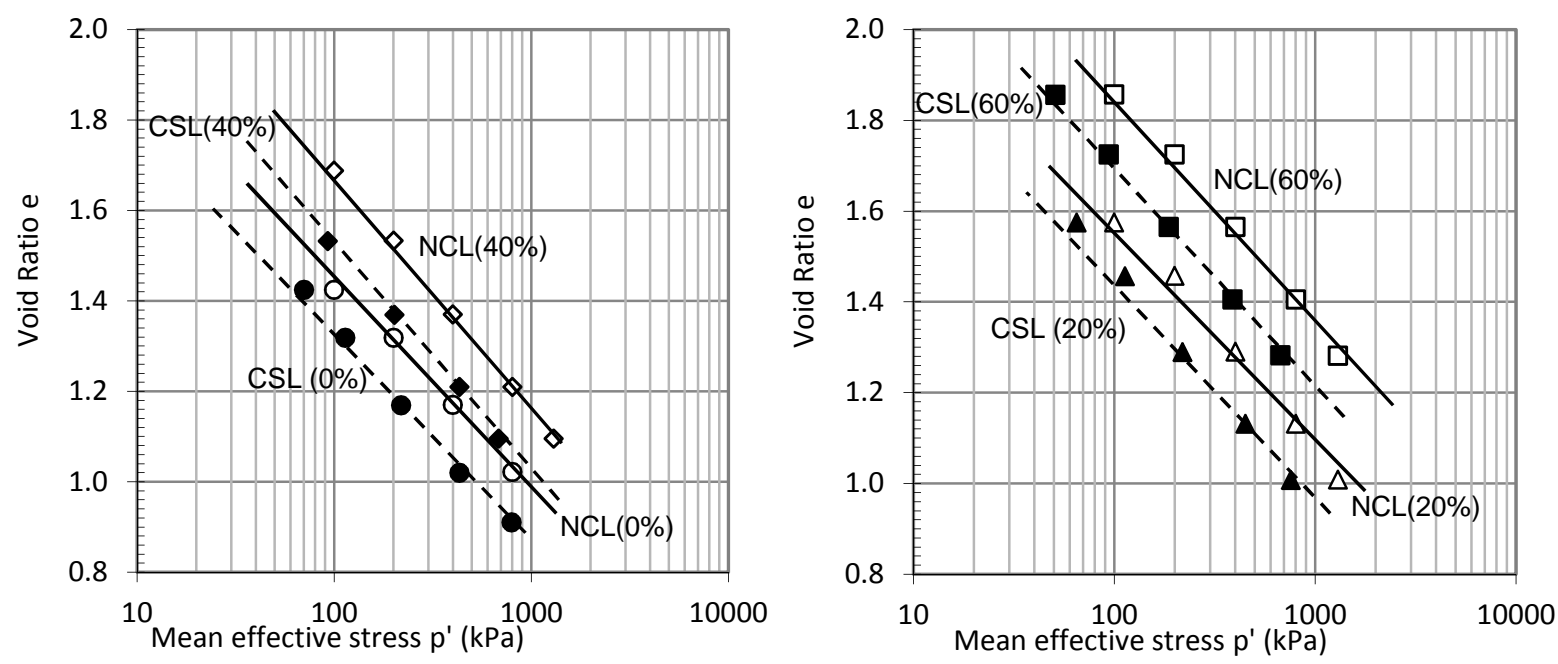

(a) Normal and critical state lines ( 0 and $40 \%$ gravel)

(b ) Normal and critical state lines (20\% and $60 \%$ gravel)

Figure 7 Pressure-volume relationship at critical state: Uniformly graded basalt 

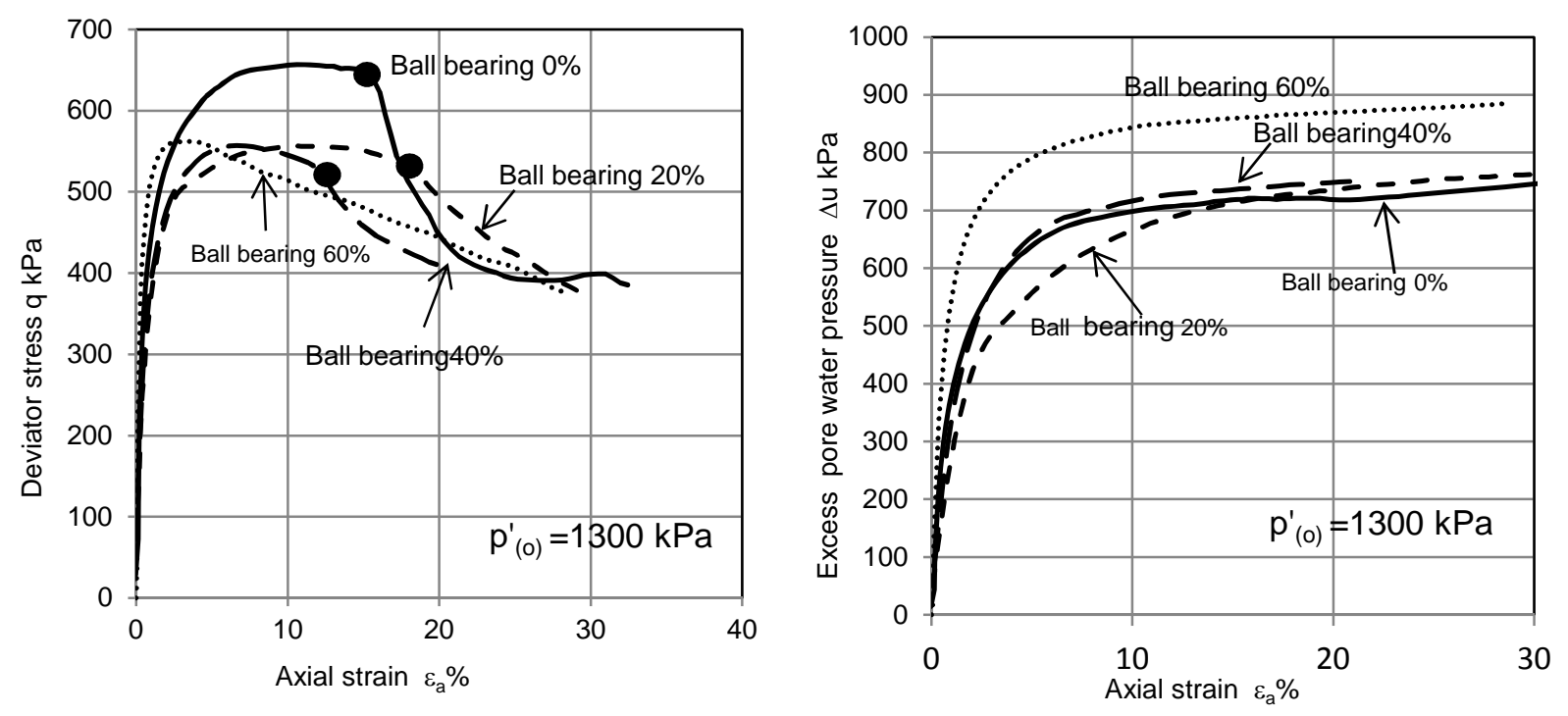

(a) Deviator stress vs axial strain

(b) Excess pore water pressure vs axial strain

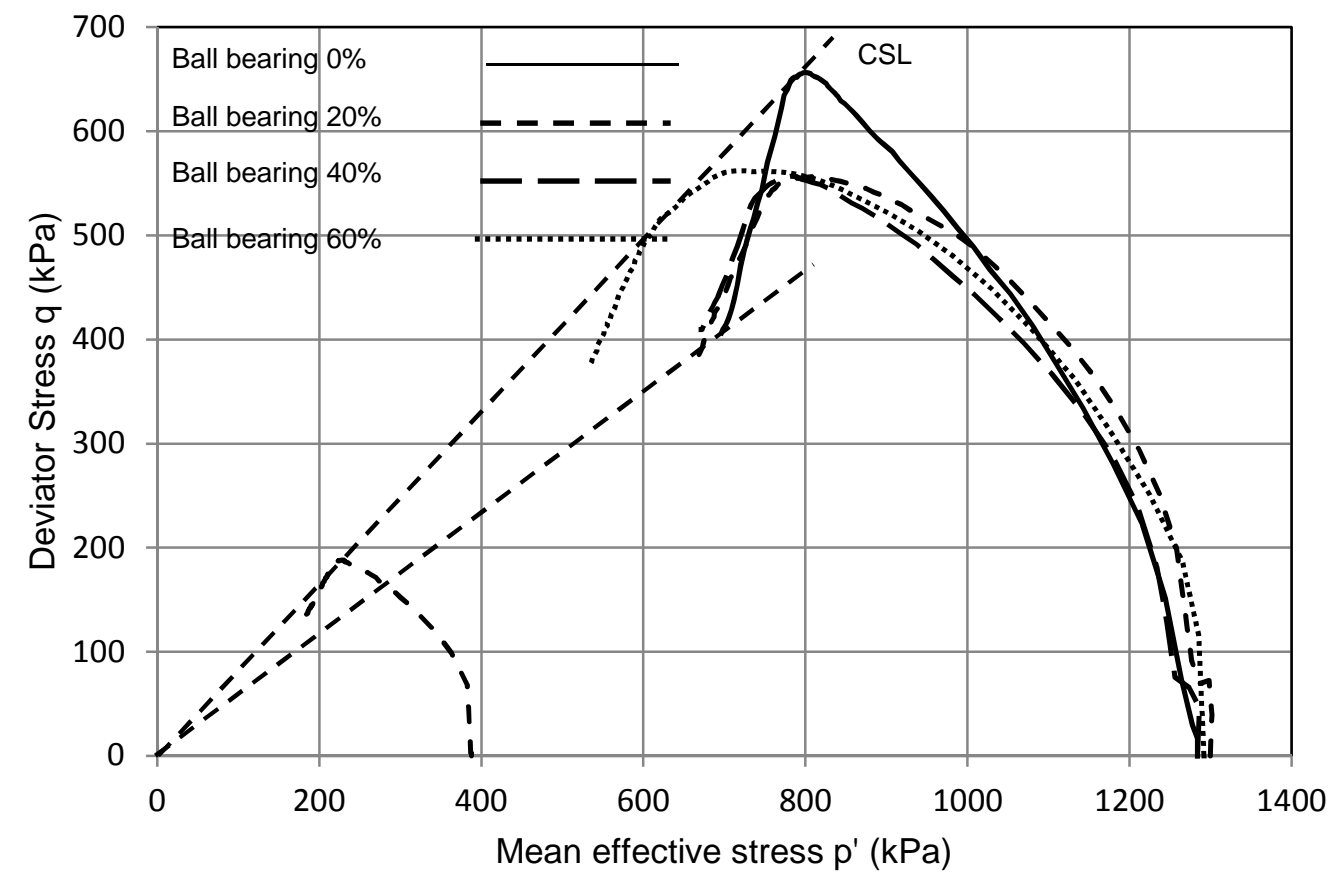

(c) Stress path

Figure 8 Stress-strain behaviour and stress paths: Ball bearings 


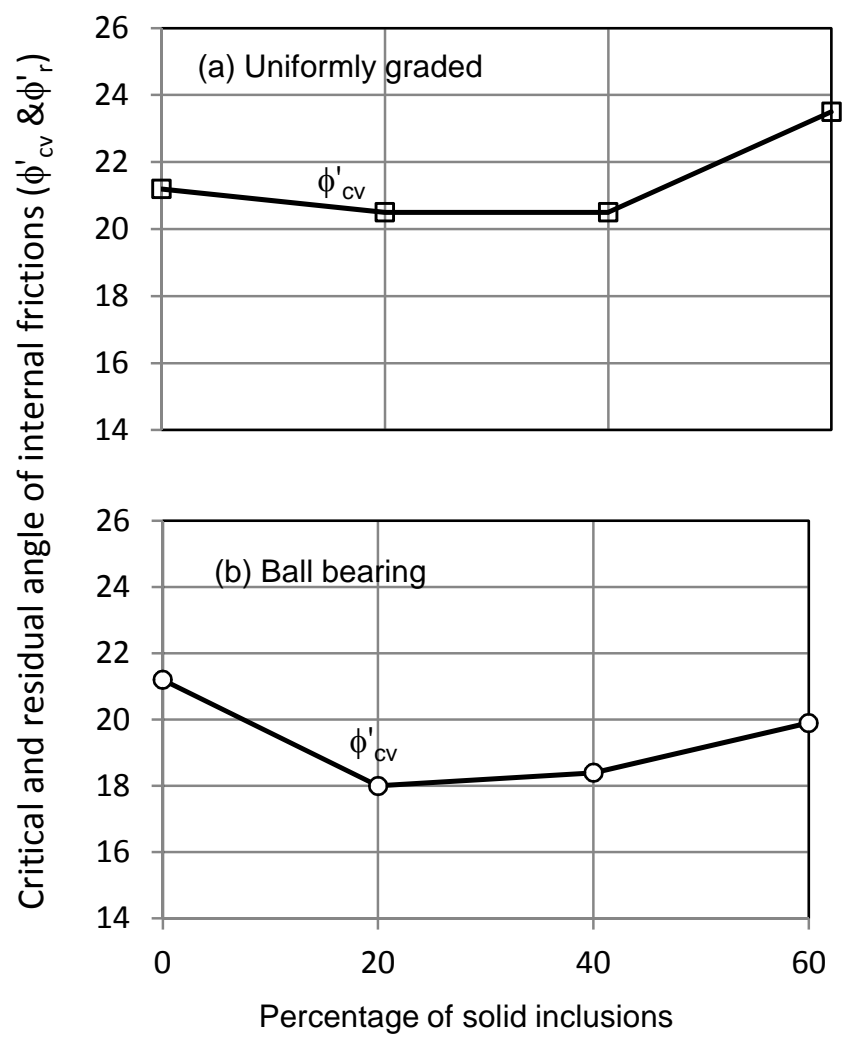

Figure 9 Effective angle of internal friction and granular contents 